\title{
Contrast Agents and Contrast-Induced Nephropathy
}

\author{
Mohammad Hassan Ghadiani' ${ }^{1}$, Pooneh Dehghan2* \\ ${ }^{1}$ Department of Nephrology, Taleghani Hospital, Shahid Beheshti University of Medical Sciences, Tehran, Iran \\ ${ }^{2}$ Taleghani Hospital Research Development Unit, Department of Imaging, Shahid Beheshti University of \\ Medical Sciences, Tehran, Iran \\ Email: "poonehdehghan@yahoo.com, ${ }^{*}$ p.dehghan@sbmu.ac.ir
}

Received 22 May 2015; accepted 30 June 2015; published 3 July 2015

Copyright (C) 2015 by authors and Scientific Research Publishing Inc.

This work is licensed under the Creative Commons Attribution International License (CC BY).

http://creativecommons.org/licenses/by/4.0/

(c) (i) Open Access

\begin{abstract}
Recent advances in medical sciences, especially in imaging, have dramatically increased the use of contrast agents. The constantly changing nature of medicine and the availability of new information, such as new pharmaceutical formulations, have necessitated periodic revisions and drafting of new guidelines for the safe use of intravenous contrast agents in radiology. This study examined the majority of guidelines, articles, and authoritative references available on the use of intravenous contrast agents in adults to reduce the risk of contrast-induced nephropathy. The search engines of PubMed, Web of Science, Scopus, and Google Scholar were used, and relevant English articles cited at least twice between 1979 and 2014 were studied. Review of the collected papers showed no consensus among them for guidelines on the incidence of contrast-induced nephropathy in patients at risk. Different formulas were used to calculate estimated glomerular filtration rate, which could be problematic in some cases. Further studies are needed for unification of existing guidelines.
\end{abstract}

\section{Keywords}

Contrast-Induced Nephropathy, Contrast Agents, Acute Kidney Injury

\section{Introduction}

Injection of contrast agents is used for computed tomography, body and coronary angiography, interventional radiology and cardiology procedures, and excretory urography. Intravenous contrast agents are divided into three main categories-hyper-osmolar, hypo-osmolar, and iso-osmolar contrast media. Hyper-osmolar contrast

${ }^{*}$ Corresponding author. 
media are ionic monomers highly hyper-osmolar to plasma ( 1400 - $1800 \mathrm{mOsmol} / \mathrm{kg})$. Low-osmolar contrast media are non-ionic monomers with lower osmolarity than hyper-osmolar contrast media but still hyper-osmolar to plasma ( $\sim 500$ - $850 \mathrm{mOsmol} / \mathrm{kg}$ ). Iso-osmolar contrast media are the most recent non-ionic contrast agents. They involve dimers with an osmolarity of $290 \mathrm{mOsmol} / \mathrm{kg}$. Therefore, these agents have lower osmolarity than the so-called "hypo-osmolar" contrast agents.

Non-ionic hypo-osmolar or iso-osmolar contrast agents are usually five to ten times safer than previous hyperosmolar types [1]. However, few isolated studies have been conducted on the effects of contrast agents on the kidneys [2]. Some studies have reported a direct or indirect association between contrast agents and the incidence of acute kidney injury (AKI), with an 11\% - 14.5\% increased risk factor [3]-[5]. Contrast-induced adverse effects are the third cause of AKI after surgery and hypotension at hospitals. The incidence of AKI ranges from $3 \%$ to $7 \%$ in patients with no risk factors and $50 \%$ in patients moderate to advanced chronic kidney disease (CKD) [6].

\section{Pathophysiology}

The exact cause of contrast-induced nephropathy is not known since hospitalized patients may still show reduced kidney function even when receiving no contrast agents. A retrospective study of 32,161 patients receiving no contrast agents reported a $25 \%$ change in creatinine levels in more than half the study population, and a $0.4 \mathrm{mg} / \mathrm{dL}$ change in over $40 \%$ of patients within 5 days [7].

The available information is related to the study of animal models associated with acute tubular necrosis (ATN) occurrence with two mechanisms of vasoconstriction and direct cytotoxic effects [8]-[16]. However, unlike classic ATN, contrast-induced nephropathy shows a quick recovery and involves a relative sodium excretion (FENa) of less than 1\% [17] [18].

Almost all intravenous contrast agents are filtered by glomeruli, and, therefore, blood flow to the renal medulla is reduced because of a change in viscosity. This effect is especially visible in iso-osmolar contrast media [9]. In patients with kidney failure, contrast agents are also secreted through other areas, including the biliary tract or alimentary canal.

Contrast agents in the plasma of people with normal renal function have a half-life of 1 - $2 \mathrm{~h}$. Almost all contrast agents are excreted by the kidneys within $24 \mathrm{~h}$ [6]. Most cases of contrast-induced nephropathy are nonoliguric and thus any iodinated contrast materials are dialyzable.

\section{Patients at Risk}

Clinically significant incidence of nephrotoxicity in healthy people with normal renal function following contrast injection either does not happen or would be extremely rare if reported [19] [20]. To identify patients at risk, measuring only serum creatinine is not enough, and estimation of glomerular ultrafiltration is essential. Serum creatinine levels depend on many factors, and creatinine clearance remains normal until glomerular ultrafiltration is reduced to $50 \%$. The following diseases/conditions can increase the risk of contrast-induced nephropathy [21]-[34] [46]-[49]:

1. A history of kidney impairment or failure, such as surgery, malignancy, dialysis, single kidney, and proteinuria, as the main risk factor, on which there is consensus.

2. Age $>60-70$ years [33] [34].

3. Use of nephrotoxic drugs and diuretics.

4. Diabetes (simultaneous presence of the disease with renal impairment significantly increases risk).

5. Use of metformin or metformin-like drugs.

6. Hyperuricemia.

7. Hypertension.

8. Congestive heart failure with low left ventricular ejection fraction and New York Heart Association Functional Classification grades 3 - 4 .

9. Acute myocardial infarction ( $>24 \mathrm{~h})$.

10. Intra-aortic balloon pump.

11. Acute hypotension.

12. Sepsis.

13. Dehydration. Contrast agents are not recommended for use in dehydrated individuals of any age, sex, and 
physical condition. Being potentially nephrotoxic, they should be avoided if possible [26].

14. A history of chemotherapy.

15. Transplantation.

16. HIV or AIDS.

17. Collagen vascular disease.

18. Multiple myeloma.

19. Low hematocrit.

20. Use of high doses of contrast agents (angiography or computed tomography with repeated injections) at short intervals i.e. $<24 \mathrm{~h}$. Hypo-osmolar contrast agents have a half-life of $2 \mathrm{~h}$. Approximately $20 \mathrm{~h}$ is needed for these materials to be thoroughly removed by the kidneys if they function normally [34]. Therefore, there should be an interval of $>24 \mathrm{~h}$ between injections if possible.

21. Cirrhosis and liver failure [6].

\section{Diagnosis}

There are no certain and standard criteria agreed upon among groups working in the field. Various definitions have been proposed, among which, the criterion of the Acute Kidney Injury Network is more comprehensive and acceptable than others. According to the definition provided by this group, AKI is an injury occurring within $48 \mathrm{~h}$ of a nephrotoxic incident (e.g. caused by contrast agents) associated with one of the following conditions [35]:

1. An increase of $\geq 0.3 \mathrm{mg} / \mathrm{dL}$ in serum creatinine level.

2. An increase of 1.5 times (50\%) in serum creatinine level.

3. A decrease of $\leq 0.5 \mathrm{~mL} / \mathrm{kg} / \mathrm{h}$ in urine output for at least $6 \mathrm{~h}$.

It should be mentioned that, usually following injection of contrast agents, serum creatinine levels are enhanced within the first $24-72 \mathrm{~h}$ but return to initial levels within 14 days [36].

Based on European Society of Urogenital Radiology criteria, contrast-induced nephropathy is defined as an increase of more than $25 \%$ or $0.5 \mathrm{mg} / \mathrm{dL}$ in the serum creatinine level within $72 \mathrm{~h}$ after the injection of contrast material, provided that no other agents can be identified that would increase the serum creatinine level [37].

Urinary sediment can be indicative of classical findings of ATN, incorporating epithelial cell casts and renal tubular cells. However, these findings are not necessary for diagnosis, nor does their absence exclude such diagnosis.

Since many contrast agents cause false-positive results in the detection of urinary protein [38], urine tests for proteinuria should not be performed for at least $24 \mathrm{~h}$ following the use of such materials, or tests should be repeated within at least $48 \mathrm{~h}$ after their initial application.

In patients with AKI after angiography, contrast-induced nephropathy should be distinguished from atheroembolic renal disease. The latter includes at least one of the following [39]:

1. Simultaneous association of other embolic events such as livedo reticularis.

2. Eosinophilia or transient reduction of complement levels.

3. Delayed injury for several days or weeks.

4. Very low recovery.

Who should be assessed for kidney function prior to injection of contrast agents, and at what intervals should injections be conducted?

Computed tomography does not necessitate serum creatinine measurement for all outpatients receiving contrast injections. Different protocols have been defined at different centers around the world.

All the prestigious English-language guidelines have listed persons at risk of developing kidney damage after contrast injection. However, the guidelines do not agree upon all the afore-mentioned groups. What is accepted by all is that measuring and estimating GFR are necessary for the first seven groups mentioned above as "patients at risk" before intravenous injection of a contrast agent. Nevertheless, creatinine and GFR estimations are essential for any candidate who is undergoing angiography with high doses of arterial injections, especially those listed above as patients at risk [33]-[41].

There is no general consensus on screening intervals (creatinine and eGFR) before contrast studies in the examined guidelines and articles, and the proposed time ranges from 7 days to 6 months. The existing resources suggest this measurement be made for high-risk hospitalized patients 7 days prior to examination [33] [37], though it is possible that it is conducted 30 days before studies for other cases [34]. 
In cases of emergency where there is no possibility of risk assessment and serum creatinine and eGFR levels are unavailable, necessary measures should be taken to prevent contrast-induced nephropathy. Such measures are discussed below [37].

Different formulas exist for eGFR [Cockcroft-Gault and Modification of Diet in Renal Disease (MDRD)]. It should be noted that the MDRD formula usually underestimates glomerular ultrafiltration compared with other formulas [42] [43], and thus must be used carefully. Using these formulas for amputations and paralysis also of those with exceptional physical conditions (e.g., severe obesity or cachexia) is less reliable and 24-h urine data should be collected to determine creatinine clearance for this group [44].

\section{Measures Taken to Reduce Risk}

The following measures should be taken to reduce the risk of contrast-induced nephropathy:

1. Use of the lowest possible dose of contrast agent.

2. Use of hypo-osmolar non-ionic monomeric contrast agents or non-ionic dimeric iso-osmular media [46]. Many centers have stopped using hyper-osmolar agents because of their numerous side effects [34].

3. Use of adequate hydration (oral or intravenous) before and after the procedure.

4. Discontinuation of nephrotoxic drugs $48 \mathrm{~h}$ before the procedure.

5. Avoidance of performing contrast studies within $24 \mathrm{~h}$ (preferably within $72 \mathrm{~h}$ ).

6. Performance of dialysis for hemodialysis patients within $24 \mathrm{~h}$ after injection. Renal impairment is not generally of concern in these patients, but what could be of concern is the osmotic load caused by the agents, which theoretically could lead to pulmonary edema and anasarca [34].

\section{Recommendations for Safe Application of Intravascular Iodinated Contrast Media}

The following algorithm is recommended:

- In patients with eGFR $>60 \mathrm{~mL} / \mathrm{min}$ : the procedure is safe (either IV or IA).

- If $45 \mathrm{~mL} / \mathrm{min}<\mathrm{eGFR}<60 \mathrm{~mL} / \mathrm{min}$, IV injection is safe but for IA injection, the patient should be well hydrated and $80 \%$ of the maximum dose of IOCM should be administered.

- If $30 \mathrm{~mL} / \mathrm{min}<\mathrm{eGFR}<45 \mathrm{~mL} / \mathrm{min}$, IA injection should be avoided and for IV injection, the patient should be well hydrated and $80 \%$ of the maximum dose of IOCM should be administered.

- In patients with eGFR $<30 \mathrm{~mL} / \mathrm{min}$, intravascular contrast study should be avoided.

[Key: IV: intravenous injections; IA: arterial injections; IOCM: iso-osmular or hypo-osmular contrast material]

There is not enough evidence to suggest the existence of an acceptable pharmaceutical treatment currently available in the market (theophylin, endothelin-1, fenoldopam, $\mathrm{N}$-acetyl-cysteine) to reduce contrast nephropathy [26] [34] [37] [45]. Yet, since N-acetyl-cysteine is not usually associated with many complications, it is still used in some centers. Nonetheless, it must be remembered that screening is not enough before processing and hydration is mandatory using this alternative.

\section{Contrast Doses}

The standard dose is $2 \mathrm{~mL} / \mathrm{kg}$, up to a maximum of $200 \mathrm{~mL} / \mathrm{kg}$.

\section{Intravenous Contrast agents in the Iranian Market}

1. Omnipaque 300 and 350: hyper-osmolar to plasma.

2. Visipaque 320: iso-osmular with plasma.

3. Ultravist 300: hypo-osmolar.

The precise roles of iso-osmular agents for the reduction of the risk of contrast-induced nephropathy are not clear. Nevertheless, it is generally accepted that this class of contrast agents produces less discomfort for patients, especially those receiving intra-arterial injections, compared with hypo-osmolar agents.

\section{Hydration Guidelines}

It is recommended that all patients receive hydrating liquids orally. The three proposed protocols for intravenous 
hydration are:

1. Infusion of $0.9 \%$ saline or sodium bicarbonate twice the amount of the contrast material [45].

2. Infusion of $0.9 \%$ saline $(1-1.5 \mathrm{~mL} / \mathrm{min} / \mathrm{h})$ for $6 \mathrm{~h}$ before or after injections, or $3 \mathrm{~mL} / \mathrm{kg} / \mathrm{h}$ and $1 \mathrm{~mL} / \mathrm{kg} / \mathrm{h}$ of sodium bicarbonate (154 mEq/L in dextrose 5\%) $6 \mathrm{~h}$ before and after injections, respectively [37].

3. Infusion of $0.9 \%$ saline or Ringer's solution $(100 \mathrm{~mL} / \mathrm{min} / \mathrm{h}) 6$ - $12 \mathrm{~h}$ before and 4 - $12 \mathrm{~h}$ after injections [34]. Giving liquids to patients with chronic heart failure or those on a limited liquid intake must be avoided.

\section{Conclusion}

The ever increasing average age of the world's population and enhanced diagnostic procedures requiring injection of contrast agents in patients with chronic renal failure are likely to increase the risk of contrast-induced nephropathy. It is essential that preventive strategies and guidelines in this area are used. The list of people at risk of contrast-enhanced nephropathy is increasing, and there is no consensus among the different schools for treatment protocols. There are many unknown and unsubstantiated points that require explanation about the incidence of contrast-enhanced nephropathy, and further research is required.

\section{References}

[1] Parfrey, P.S., Griffiths, S.M., Barrett, B.J., et al. (1989) Contrast Material-Induced Renal Failure in Patients with Diabetes Mellitus, Renal Insufficiency, or Both. A Prospective Controlled Study. New England Journal of Medicine, 320, 143-149. http://dx.doi.org/10.1056/NEJM198901193200303

[2] Rudnick, M.R., Goldfarb, S., Wexler, L., et al. (1995) Nephrotoxicity of Ionic and Nonionic Contrast Media in 1196 Patients: A Randomized Trial. The Iohexol Cooperative Study. Kidney International, 47, 254-261. http://dx.doi.org/10.1038/ki.1995.32

[3] Davidson, C.J., Hlatky, M., Morris, K.G., et al. (1989) Cardiovascular and Renal Toxicity of a Nonionic Radiographic Contrast Agent after Cardiac Catheterization. A Prospective Trial. Annals of Internal Medicine, 110, 119-124. http://dx.doi.org/10.7326/0003-4819-110-2-119

[4] Schwab, S.J., Hlatky, M.A., Pieper, K.S., et al. (1989) Contrast Nephrotoxicity: A Randomized Controlled Trial of a Nonionic and an Ionic Radiographic Contrast Agent. New England Journal of Medicine, 320, 149-153. http://dx.doi.org/10.1056/NEJM198901193200304

[5] Cigarroa, R.G., Lange, R.A., Williams, R.H. and Hillis, L.D. (1989) Dosing of Contrast Material to Prevent Contrast Nephropathy in Patients with Renal Disease. American Journal of Medicine, 86, 649-652. http://dx.doi.org/10.1016/0002-9343(89)90437-3

[6] Lautin, E.M., Freeman, N.J., Schoenfeld, A.H., et al. (1991) Radiocontrast-Associated Renal Dysfunction: Incidence and Risk Factors. American Journal of Roentgenology, 157, 49-58. http://dx.doi.org/10.2214/ajr.157.1.2048539

[7] Lautin, E.M., Freeman, N.J., Schoenfeld, A.H., et al. (1991) Radiocontrast-Associated Renal Dysfunction: A Comparison of Lower-Osmolality and Conventional High-Osmolality Contrast Media. American Journal of Roentgenology, 157, 59-65. http://dx.doi.org/10.2214/ajr.157.1.2048540

[8] Rudnick, M.R., Berns, J.S., Cohen, R.M. and Goldfarb, S. (1994) Nephrotoxic Risks of Renal Angiography: Contrast Media-Associated Nephrotoxicity and Atheroembolism-A Critical Review. American Journal of Kidney Diseases, 24, 713-727. http://dx.doi.org/10.1016/S0272-6386(12)80235-6

[9] Barrett, B.J. (1994) Contrast Nephrotoxicity. Journal of the American Society of Nephrology, 5, 125.

[10] Solomon, R. (1998) Contrast-Medium-Induced Acute Renal Failure. Kidney International, 53, 230-242. http://dx.doi.org/10.1038/sj.ki.4495510

[11] Weisbord, S.D. and Palevsky, P.M. (2005) Radiocontrast-Induced Acute Renal Failure. Journal of Intensive Care Medicine, 20, 63-75. http://dx.doi.org/10.1177/0885066604273503

[12] Detrenis, S., Meschi, M., Musini, S. and Savazzi, G. (2005) Lights and Shadows on the Pathogenesis of Contrast-Induced Nephropathy: State of the Art. Nephrology Dialysis Transplantation, 20, 1542-1550. http://dx.doi.org/10.1093/ndt/gfh868

[13] Persson, P.B., Hansell, P. and Liss, P. (2005) Pathophysiology of Contrast Medium-Induced Nephropathy. Kidney International, 68, 14-22. http://dx.doi.org/10.1111/j.1523-1755.2005.00377.x

[14] Heyman, S.N., Rosenberger, C. and Rosen, S. (2005) Regional Alterations in Renal Haemodynamics and Oxygenation: A Role in Contrast Medium-Induced Nephropathy. Nephrology Dialysis Transplantation, 20, i6-i11. http://dx.doi.org/10.1093/ndt/gfh1069

[15] Agmon, Y., Peleg, H., Greenfeld, Z., et al. (1994) Nitric Oxide and Prostanoids Protect the Renal Outer Medulla from 
Radiocontrast Toxicity in the Rat. Journal of Clinical Investigation, 94, 1069-1075. http://dx.doi.org/10.1172/JCI117421

[16] Weisberg, L.S., Kurnik, P.B. and Kurnik, B.R. (1992) Radiocontrast-Induced Nephropathy in Humans: Role of Renal Vasoconstriction. Kidney International, 41, 1408-1415. http://dx.doi.org/10.1038/ki.1992.206

[17] Cantley, L.G., Spokes, K., Clark, B., et al. (1993) Role of Endothelin and Prostaglandins in Radiocontrast-Induced Renal Artery Constriction. Kidney International, 44, 1217-1223. http://dx.doi.org/10.1038/ki.1993.371

[18] Katholi, R.E., Taylor, G.J., McCann, W.P., et al. (1995) Nephrotoxicity from Contrast Media: Attenuation with Theophylline. Radiology, 195, 17-22. http://dx.doi.org/10.1148/radiology.195.1.7892462

[19] Russo, D., Minutolo, R., Cianciaruso, B., et al. (1995) Early Effects of Contrast Media on Renal Hemodynamics and Tubular Function in Chronic Renal Failure. Journal of the American Society of Nephrology, 6, 1451-1458.

[20] Pflueger, A., Larson, T.S., Nath, K.A., et al. (2000) Role of Adenosine in Contrast Media-Induced Acute Renal Failure in Diabetes Mellitus. Mayo Clinic Proceedings, 75, 1275-1283. http://dx.doi.org/10.4065/75.12.1275

[21] Molitoris, B.A., Dahl, R. and Geerdes, A. (1992) Cytoskeleton Disruption and Apical Redistribution of Proximal Tubule $\mathrm{Na}(+)-\mathrm{K}(+)$-ATPase during Ischemia. American Journal of Physiology, 263, F488-F495.

[22] Fang, L.S., Sirota, R.A., Ebert, T.H. and Lichtenstein, N.S. (1980) Low Fractional Excretion of Sodium with Contrast Media-Induced Acute Renal Failure. Archives of Internal Medicine, 140, 531. http://dx.doi.org/10.1001/archinte.1980.00330160091033

[23] Wang, A., Holcslaw, T., Bashore, T.M., et al. (2000) Exacerbation of Radiocontrast Nephrotoxicity by Endothelin Receptor Antagonism. Kidney International, 57, 1675-1680. http://dx.doi.org/10.1046/j.1523-1755.2000.00012.x

[24] Tumlin, J.A., Wang, A., Murray, P.T. and Mathur, V.S. (2002) Fenoldopam Mesylate Blocks Reductions in Renal Plasma Flow after Radiocontrast Dye Infusion: A Pilot Trial in the Prevention of Contrast Nephropathy. American Heart Journal, 143, 894-903. http://dx.doi.org/10.1067/mhj.2002.122118

[25] Heyman, S.N., Rosen, S. and Rosenberger, C. (2008) Renal Parenchymal Hypoxia, Hypoxia Adaptation, and the Pathogenesis of Radiocontrast Nephropathy. Clinical Journal of the American Society of Nephrology, 3, 288-296. http://dx.doi.org/10.2215/CJN.02600607

[26] Heinrich, M.C., Kuhlmann, M.K., Grgic, A., et al. (2005) Cytotoxic Effects of Ionic High-Osmolar, Nonionic Monomeric, and Nonionic Iso-Osmolar Dimeric Iodinated Contrast Media on Renal Tubular Cells in Vitro. Radiology, 235, 843-849. http://dx.doi.org/10.1148/radiol.2353040726

[27] Yoshioka, T., Fogo, A. and Beckman, J.K. (1992) Reduced Activity of Antioxidant Enzymes Underlies Contrast Media-Induced Renal Injury in Volume Depletion. Kidney International, 41, 1008-1015. http://dx.doi.org/10.1038/ki.1992.153

[28] Goodman, A.I., Olszanecki, R., Yang, L.M., et al. (2007) Heme Oxygenase-1 Protects against Radiocontrast-Induced Acute Kidney Injury by Regulating Anti-Apoptotic Proteins. Kidney International, 72, 945-953. http://dx.doi.org/10.1038/sj.ki.5002447

[29] Newhouse, J.H., Kho, D., Rao, Q.A. and Starren, J. (2008) Frequency of Serum Creatinine Changes in the Absence of Iodinated Contrast Material: Implications for Studies of Contrast Nephrotoxicity. American Journal of Roentgenology, 191, 376-382. http://dx.doi.org/10.2214/AJR.07.3280

[30] Aspelin, P., Aubry, P., Fransson, S.G., et al. (2003) Nephrotoxic Effects in High-Risk Patients Undergoing Angiography. New England Journal of Medicine, 348, 491-499. http://dx.doi.org/10.1056/NEJMoa021833

[31] Brar, S.S., Shen, A.Y., Jorgensen, M.B., et al. (2008) Sodium Bicarbonate vs Sodium Chloride for the Prevention of Contrast Medium-Induced Nephropathy in Patients Undergoing Coronary Angiography: A Randomized Trial. JAMA, 300, 1038. http://dx.doi.org/10.1001/jama.300.9.1038

[32] Heinrich, M.C., Häberle, L., Müller, V., et al. (2009) Nephrotoxicity of Iso-Osmolar Iodixanol Compared with Nonionic Low-Osmolar Contrast Media: Meta-Analysis of Randomized Controlled Trials. Radiology, 250, 68-86. http://dx.doi.org/10.1148/radiol.2501080833

[33] Rudnick, M.R., Davidson, C., Laskey, W., et al. (2008) Nephrotoxicity of Iodixanol versus Ioversol in Patients with Chronic Kidney Disease: The Visipaque Angiography/Interventions with Laboratory Outcomes in Renal Insufficiency (VALOR) Trial. American Heart Journal, 156, 776-782. http://dx.doi.org/10.1016/j.ahj.2008.05.023

[34] Solomon, R.J., Mehran, R., Natarajan, M.K., et al. (2009) Contrast-Induced Nephropathy and Long-Term Adverse Events: Cause and Effect? Clinical Journal of the American Society of Nephrology, 4, 1162-1169. http://dx.doi.org/10.2215/CJN.00550109

[35] Rihal, C.S., Textor, S.C., Grill, D.E., et al. (2002) Incidence and Prognostic Importance of Acute Renal Failure after Percutaneous Coronary Intervention. Circulation, 105, 2259-2264. http://dx.doi.org/10.1161/01.CIR.0000016043.87291.33 
[36] McCullough, P.A., Wolyn, R., Rocher, L.L., et al. (1997) Acute Renal Failure after Coronary Intervention: Incidence, Risk Factors, and Relationship to Mortality. The American Journal of Medicine, 103, 368-375. http://dx.doi.org/10.1016/S0002-9343(97)00150-2

[37] Nikolsky, E., Mehran, R., Lasic, Z., et al. (2005) Low Hematocrit Predicts Contrast-Induced Nephropathy after Percutaneous Coronary Interventions. Kidney International, 67, 706-713. http://dx.doi.org/10.1111/j.1523-1755.2005.67131.x

[38] Mehran, R., Aymong, E.D., Nikolsky, E., et al. (2004) A Simple Risk Score for Prediction of Contrast-Induced Nephropathy after Percutaneous Coronary Intervention: Development and Initial Validation. Journal of the American College of Cardiology, 44, 1393-1399. http://dx.doi.org/10.1016/j.jacc.2004.06.068

[39] Barrett, B.J., Parfrey, P.S., Vavasour, H.M., et al. (1992) Contrast Nephropathy in Patients with Impaired Renal Function: High versus Low Osmolar Media. Kidney International, 41, 1274-1279. http://dx.doi.org/10.1038/ki.1992.189

[40] Manske, C.L., Sprafka, J.M., Strony, J.T. and Wang, Y. (1990) Contrast Nephropathy in Azotemic Diabetic Patients Undergoing Coronary Angiography. The American Journal of Medicine, 89, 615-620. http://dx.doi.org/10.1016/0002-9343(90)90180-L

[41] Weisbord, S.D., Mor, M.K., Resnick, A.L., et al. (2008) Incidence and Outcomes of Contrast-Induced AKI Following Computed Tomography. Clinical Journal of the American Society of Nephrology, 3, 1274-1281. http://dx.doi.org/10.2215/CJN.01260308

[42] Mitchell, A.M., Jones, A.E., Tumlin, J.A. and Kline, J.A. (2010) Incidence of Contrast-Induced Nephropathy after Contrast-Enhanced Computed Tomography in the Outpatient Setting. Clinical Journal of the American Society of Nephrology, 5, 4-9. http://dx.doi.org/10.2215/CJN.05200709

[43] McCarthy, C.S. and Becker, J.A. (1992) Multiple Myeloma and Contrast Media. Radiology, 183, 519-521. http://dx.doi.org/10.1148/radiology.183.2.1561361

[44] Holland, M.D., Galla, J.H., Sanders, P.W. and Luke, R.G. (1985) Effect of Urinary pH and Diatrizoate on Bence Jones Protein Nephrotoxicity in the Rat. Kidney International, 27, 46-50. http://dx.doi.org/10.1038/ki.1985.8

[45] Stolker, J.M., McCullough, P.A., Rao, S., et al. (2010) Pre-Procedural Glucose Levels and the Risk for Contrast-Induced Acute Kidney Injury in Patients Undergoing Coronary Angiography. Journal of the American College of Cardiology, 55, 1433-1440. http://dx.doi.org/10.1016/j.jacc.2009.09.072

[46] Rim, M.Y., Ro, H., Kang, W.C., et al. (2012) The Effect of Renin-Angiotensin-Aldosterone System Blockade on Contrast-Induced Acute Kidney Injury: A Propensity-Matched Study. American Journal of Kidney Diseases, 60, 576-582. http://dx.doi.org/10.1053/j.ajkd.2012.04.017

[47] Rosenstock, J.L., Bruno, R., Kim, J.K., et al. (2008) The Effect of Withdrawal of ACE Inhibitors or Angiotensin Receptor Blockers Prior to Coronary Angiography on the Incidence of Contrast-Induced Nephropathy. International Urology and Nephrology, 40, 749-755. http://dx.doi.org/10.1007/s11255-008-9368-1

[48] Rich, M.W. and Crecelius, C.A. (1990) Incidence, Risk Factors, and Clinical Course of Acute Renal Insufficiency after Cardiac Catheterization in Patients 70 Years of Age or Older. A Prospective Study. Archives of Internal Medicine, 150, 1237. http://dx.doi.org/10.1001/archinte.1990.00390180067011

[49] Morcos, S.K., el-Nahas, A.M., Brown, P. and Haylor, J. (1992) Effect of Iodinated Water Soluble Contrast Media on Urinary Protein Assays. BMJ, 305, 29. http://dx.doi.org/10.1136/bmj.305.6844.29-a 